\title{
Public health nutrition capacity: assuring the quality of workforce preparation for scaling up nutrition programmes
}

\author{
Roger Shrimpton ${ }^{1, *}$, Lisanne M du Plessis ${ }^{2}$, Hélène Delisle ${ }^{3}$, Sonia Blaney ${ }^{4}$, \\ Stephen J Atwood ${ }^{5}$, David Sanders ${ }^{6}$, Barrie Margetts ${ }^{7}$ and Roger Hughes ${ }^{8}$ on behalf \\ of the WPHNA Capacity Building Task Force \\ 'Department of Global Community Health and Behavioural Sciences, Tulane School of Public Health and Tropical \\ Medicine, 1440 Canal Street, New Orleans, LA 701 12, USA: ${ }^{2}$ Faculty of Medicine and Health Sciences, \\ Stellenbosch University, Tygerberg, South Africa: ${ }^{3}$ Département de nutrition, Faculté de Médecine, Université de \\ Montréal, Montréal, QC, Canada: ${ }^{4}$ École des sciences des aliments, de nutrition et d'études familiales, Faculté des \\ sciences de la santé et des services communautaires, Université de Moncton, Moncton, NB, Canada: ${ }^{5}$ School of \\ Global Studies, Thammasat University, Rangsit, Pathum Thani, Thailand: 'School of Public Health, University of the \\ Western Cape, Bellville, South Africa: ${ }^{7}$ Faculty of Medicine, University of Southampton, Southampton, UK: ${ }^{8}$ Faculty \\ of Health Sciences and Medicine, Bond University, Gold Coast, QLD, Australia
}

Submitted 22 July 2015: Final revision received 13 December 2015: Accepted 16 December 2015: First published online 9 February 2016

\begin{abstract}
Objective: To describe why and how capacity-building systems for scaling up nutrition programmes should be constructed in low- and middle-income countries (LMIC).

Design: Position paper with task force recommendations based on literature review and joint experience of global nutrition programmes, public health nutrition (PHN) workforce size, organization, and pre-service and in-service training.

Setting: The review is global but the recommendations are made for LMIC scaling up multisectoral nutrition programmes.

Subjects: The multitude of PHN workers, be they in the health, agriculture, education, social welfare, or water and sanitation sector, as well as the community workers who ensure outreach and coverage of nutrition-specific and -sensitive interventions.

Results: Overnutrition and undernutrition problems affect at least half of the global population, especially those in LMIC. Programme guidance exists for undernutrition and overnutrition, and priority for scaling up multisectoral programmes for tackling undernutrition in LMIC is growing. Guidance on how to organize and scale up such programmes is scarce however, and estimates of existing PHN workforce numbers - although poor - suggest they are also inadequate. Pre-service nutrition training for a PHN workforce is mostly clinical and/or food science oriented and in-service nutrition training is largely restricted to infant and young child nutrition.

Conclusions: Unless increased priority and funding is given to building capacity for scaling up nutrition programmes in LMIC, maternal and child undernutrition rates are likely to remain high and nutrition-related non-communicable diseases to escalate. A hybrid distance learning model for PHN workforce managers' in-service training is urgently needed in LMIC.
\end{abstract}

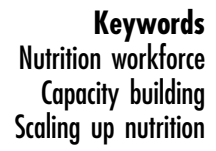

Malnutrition is increasingly recognized as one of the principal and growing causes of global disease and mortality, affecting at least half of the world's inhabitants. Malnutrition here includes both undernutrition and overnutrition as a 'double burden of malnutrition' occurring across the life course of individuals ${ }^{(1)}$ and often coexisting in the same communities and even the same households, affecting both rich and poor countries alike ${ }^{(2)}$. While young child stunting, reflecting both maternal and child undernutrition, is affecting about a quarter of the world's children $^{(3)}$, overweight and obesity affects about one in three adults and one in ten children ${ }^{(4)}$. Anaemia, principally 
due to iron deficiency, is also affecting about a third of women of reproductive age and almost half of preschool children ${ }^{(5)}$. Maternal and child undernutrition in the aggregate is a cause of 3.1 million child deaths annually or $45 \%$ of all child deaths in 2011. Indeed, fourteen of the top twenty determinants of global deaths are related to diet and nutrition ${ }^{(6)}$. Obesity is itself a chronic disease and the 'metabolic syndrome', which includes abdominal obesity, dyslipidaemia, hypertension and impaired glucose tolerance, increases the risk of developing CVD twofold and type 2 diabetes threefold ${ }^{(7)}$. The cost of treating non-communicable diseases, of which nutrition-related non-communicable diseases are the major share, is likely to be \$US 30 trillion globally over the next 20 years ${ }^{(8)}$. Adult obesity rates began to rise in all developed countries around the middle of the 1980s, thought to be related to changes in both the food system and community environments ${ }^{(9)}$, and are now rising in most low- and middle-income countries (LMIC) ${ }^{(10)}$.

Nutrition has been increasingly thrust into the global development spotlight in this new millennium and a considerable momentum to tackle nutrition problems has been created. The World Bank began mainstreaming nutrition in country-level development planning just over a decade ago in accordance with its new nutrition strategy ${ }^{(11)}$. The Scaling Up Nutrition (SUN) movement was formed at a UN Millennium Development Goal Summit in September 2010, and the Framework for Action to Scale Up Nutrition (SUN Framework) was endorsed by over a hundred entities from national governments, the UN system, civil society organizations, development agencies, academia, philanthropic bodies and the private sector. Subsequently a SUN Road Map was elaborated ${ }^{(12)}$ which anticipated that in 'SUN countries' there would be multi-stakeholder platforms, with improved sharing of experiences, better support for monitoring of progress, better alignment of assistance from development partners, and stronger governance and coordination of intergovernmental action. At the latest reckoning fifty-five countries had joined the SUN movement, in which fortyfour had established high-level coordination mechanisms and at least twenty had developed updated and budgeted multisectoral nutrition plans ${ }^{(13)}$. The recently completed SUN review has also recommended that SUN should progressively include the double burden of malnutrition, as most LMIC are increasingly having to face both problems $^{(14)}$.

In 2012 the World Health Assembly passed a resolution that endorsed and urged member states to put into practice a Comprehensive Implementation Plan on maternal, infant and young child nutrition ${ }^{(15)}$, with six global targets for $2025^{(16)}$ including: (i) a $40 \%$ reduction in young child stunting; (ii) a $50 \%$ reduction in anaemia in women of reproductive age; (iii) a $30 \%$ reduction in low birth weight; (iv) no increase in childhood overweight; (v) an increase to $50 \%$ in the rate of exclusive breast-feeding in the first
6 months; and (vi) reduce and maintain childhood wasting to less than 5\%. In 2013 the World Health Assembly endorsed the WHO Global Action Plan for the Prevention and Control of Noncommunicable Diseases 2013-2020 (17) together with nine voluntary global targets including that of a $25 \%$ relative reduction in premature mortality from non-communicable diseases by 2025 , as well as a $0 \%$ increase in diabetes/obesity, a $25 \%$ reduction in raised blood pressure and a $30 \%$ reduction in salt/sodium intake. In 2015 the World Health Assembly approved a global monitoring framework for the Comprehensive Implementation Plan with a core set of fourteen indicators: five on intermediate outcomes, six on process and three on policy environment and capacity ${ }^{(18)}$. The Comprehensive Implementation Plan further established that member states should include a comprehensive approach to capacity building and workforce development, with the capacity indicator being the number of nutrition professionals per 100000 population.

Nutrition capacity is often weak in LMIC especially, largely related to the absence of common understanding of the malnutrition problem ${ }^{(19)}$. This lack of understanding as well as the relatively recent development of public health nutrition (PHN) science have undoubtedly contributed to the shortage of professionals capable of developing population-based approaches for the prevention of all forms of malnutrition as opposed to (or in addition to) a cadre capable of treating the consequences in individuals. A consensus is certainly growing that a robust and knowledgeable workforce is essential for PHN policy implementation ${ }^{(20)}$. How to build that capacity is the question that still needs to be answered however, especially in LMIC.

The purpose of the present position paper is to lay out the case for, as well as to define, the desirable characteristics of a system for developing the capacity of nutrition workforces for scaling up nutrition programmes in LMIC especially. In order to do this, based on evidence drawn from the literature as well as the joint experience of the Task Force, the existing nutrition workforce capacity and the potential mechanisms for building such capacity in LMIC are described.

\section{Methodology}

Although a position paper would not normally include a methodology section, due to the rich nature of the process leading to this consensus set of recommendations it was considered essential to include this description. The World Public Health Nutrition Association (WPHNA) Capacity Building Task Force, since its establishment in Porto in 2008,* has developed a competency framework ${ }^{(21)}$ providing the architecture for PHN workforce development, as well as operationalized an individual practitioner

*http://wphna.org/capacity-building/ (accessed June 2015). 
certification system* to provide a mechanism for professional recognition. At the 2012 conference in Rio de Janeiro case studies of nutrition capacity for six countries were presented and discussed. $\dagger$ Subsequently a practice framework was developed ${ }^{(22)}$ which was used to assess capacity in several countries of $\mathrm{Asia}^{(23-25)}$, leading to a series of recommendation as to the short-, medium- and long-term approaches needed to strengthen PHN workforce capacity in Asia in particular ${ }^{(26)}$. At the 2014 conference in Oxford the Task Force discussed ways of assuring the quality of nutrition workforce preparation, be it through a university programme accreditation system for pre-service training or by setting standards for on-the-job training of specialist public health nutritionists as well as in-service training of other members of the PHN workforce. Minutes of that meeting can be found on the WPHNA website. In preparation for the Oxford meeting a review paper was developed as a basis for discussion among the Task Force, which looked at the global mechanisms and materials available for developing multisectoral capacity in nutrition. That review was based on searches of the literature using PubMed and Google, as well as drawing on the conclusions and recommendations coming from the Asian assessments especially. Members of the Task Force were invited to comment on the review paper and to agree to the conclusions and recommendations. Those who agreed to do so and provided comments are those included as the named authors of this position paper.

\section{The public health nutrition workforce}

\section{Nutrition programmes}

Programmes for tackling maternal and child undernutrition have gained impetus from the Lancet Nutrition Series published in 2008 and 2013 which have helped create a consensus around a package of effective interventions. The nutrition-specific interventions ${ }^{(27)}$ for reducing maternal and child undernutrition are mostly delivered through the health sector and directed at immediate levels of causality, while nutrition-sensitive interventions ${ }^{(28)}$ are delivered through other sectors such as education, agriculture, water and sanitation, and social welfare, and directed at the underlying and basic levels of causality. However, much less consensus has yet been created around the interventions needed to reduce overnutrition. The WHO has recommend that childhood obesity prevention programmes $^{(29)}$ should include both 'top-down' as well as community-based actions, along with a mixture of policy instruments including: (i) legislative and financial tools, to ensure availability and affordability of healthy foods and physical activity opportunities; (ii) interventions across a

*http://wphna.org/certification-scheme/ (accessed June 2015).

†http://wphna.org/wp-content/uploads/2013/01/CB-Symposium-presentationHughes.pdf (accessed June 2015).

†http://wphna.org/wp-content/uploads/2013/01/Oxford-Capacity-Workshopminute-01-10.pdf (accessed June 2015). range of settings, including early childcare settings, schools and community organizations; and (iii) the establishment of cross-sectoral platforms and a multisectoral approach. Initial results of such community-based efforts in France suggest that this sort of approach works ${ }^{(30)}$.

The importance of employing multisectoral approaches for improving maternal and child undernutrition, often justified on the basis of 'sustainability', has been widely agreed during this last decade ${ }^{(11,31,32)}$. Documented experience of how multisector programmes are implemented is quite rare however ${ }^{(33-35)}$, with little or no guidance existing on how to develop and manage such programmes. Indeed, while many countries report having national multisector nutrition plans, it seems that very few of them are actually being implemented at any scale ${ }^{(36)}$. A key lesson from history over the past 65 years is that international health agendas have tended to fluctuate between a focus on technology-based medical care and public health interventions, and an understanding of health as a social phenomenon requiring more complex forms of intersectoral policy action ${ }^{(37)}$. The complex and multisectoral nature of maternal and child undernutrition may explain why it has not been effectively addressed, even though many of the solutions are now known.

Considerable agreement exists that community-based health and nutrition programmes are needed if the rates of reduction of maternal and child undernutrition are to be accelerated. Such programmes can be very successful, especially if they have the essential elements of community ownership, adequate population coverage, targeting, and central support for supplies and training ${ }^{(38)}$. Well-run community-based nutrition programmes costing about \$US 5 per household per year can achieve an annual reduction of child undernutrition rates of -1.5 percentage points per year ${ }^{(39)}$. In order to deliver such impact a certain level of intensity of effort has to be ensured, with optimal ratios of not more than twenty mobilizers, or community health workers (CHW), per facilitator/ supervisor and not more than twenty households per mobilizer. If these levels of intensity of effort are not ensured with a sufficiently wide coverage, then no impact will be seen at the population level, and so the resources invested are largely lost. A global analysis of the work of CHW confirmed that they provide a critical link between communities and their health and social service systems ${ }^{(40)}$. The CHW volunteers typically receive some locally organized cascade training in order to be able to carry out their work, often from trainers who do not themselves have capacity to train health workers, but there does not appear to be any national or international standard for these. The review ${ }^{(40)}$ recommended that community-based programmes should be inserted into the wider health system and that CHW be included in health human resource planning. A recent systematic review of strategies used to build practitioners' capacity to implement community-based interventions found them to be 


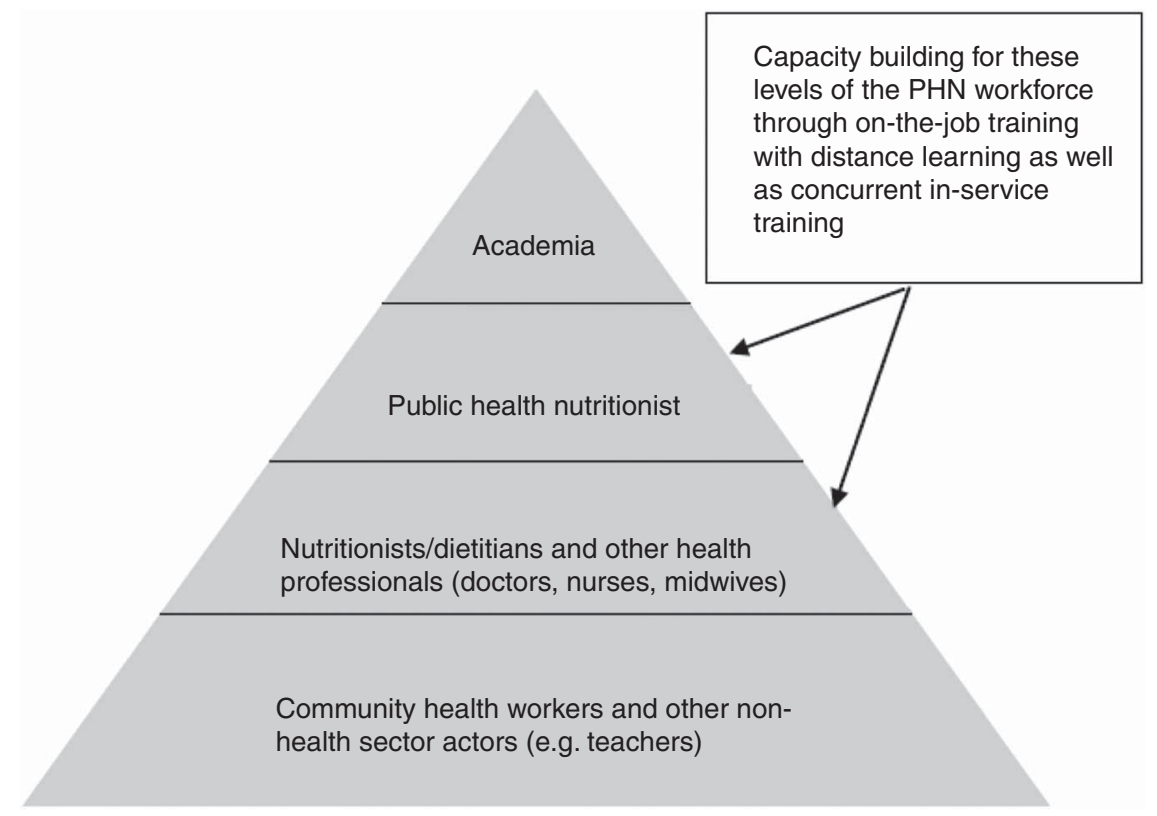

Fig. 1 Multilayered public health nutrition (PHN) workforce development

effective at increasing practitioners' adoption and implementation of evidence-based interventions ${ }^{(41)}$.

\section{Workforce structure}

While the ideal structure of a PHN workforce at the lower levels of the health system (i.e. district level) is reasonably well agreed upon, at least among this Task Force, the same cannot be said for the ideal structure and organization of the existing workforce across sectors and levels of government. The idealized PHN structure includes a pyramid (see Fig. 1) with a specialist PHN professional as the manager at the pinnacle, overseeing the work in the district of other health staff and related staff from other sectors ${ }^{(21)}$. The pyramidal structure represents numbers, not a hierarchical relationship. The specialist PHN manager should have oversight of the delivery of all curative and preventive nutrition interventions delivered through the health system in the district and work towards ensuring their best possible impact. The delivery of such interventions is typically done by others including nurses, midwives, dietitians and doctors, who in turn may provide support to other non-health actors in the district including CHW, teachers, agricultural extension workers and social workers as examples.

\section{Workforce size}

Estimates of the numbers of PHN specialists are few, but all suggest that these professionals are either insufficient and/or largely missing in most national nutrition/health workforces. In West Africa alone (population 300 million) it was estimated that 1800 new Bachelor-level graduates in nutrition would be needed to fill positions as programme implementers/managers $^{(42)}$ (if they existed). More recently in West Africa a critical shortage of skilled nutrition professionals was detected in all thirteen countries surveyed $^{(43)}$, with limited supervision of nutrition activities, especially at the level of implementation by front-line health workers. Nigeria and Ghana emerged as the countries with the greatest capacities to support the expansion of a nutrition workforce, although a significant proportion of their trained nutritionists were not employed in the public sector. Bangladesh ${ }^{(25)}$ and Nepal ${ }^{(24)}$ have no PHN specialists employed in their public workforce.

Doctors, nurses and midwives (as well as dietitians in some countries) make up the great majority of workers currently entrusted to deliver nutrition interventions globally. In West Africa the nutrition training of these health professionals was found to be particularly poor ${ }^{(44)}$, and a similar situation is likely to exist in most LMIC. The Asian regional country case studies carried out by UNICEF and the WPHNA with European Union support concluded that the nutritional knowledge of health workers was outdated, their nutrition competencies limited to more clinical and curative activities, and for nurses and midwives especially their job descriptions did not include nutrition responsibilities ${ }^{(26)}$. Such a situation is hardly a surprise however, as even in the $\mathrm{USA}^{(45)}$ and the $\mathrm{UK}^{(46)}$ the nutrition content of nurses' and medical doctors' training is also considered outdated and inadequate. Stellar work has been carried out in Canada to strengthen dietitians' capacity in $\mathrm{PHN}^{(47)}$, with several short online courses for continuing education of dietitians/nutritionists under the leadership of the Dietitians of Canada professional association.* However, in many LMIC health staff

*http://www.dietitians.ca/Learn/Learning-On-Demand/Online-Courses.aspx (accessed December 2015). 
are also very often inequitably distributed, with shortages as well as inappropriate skill mixes especially at lower levels of the system. In most countries studied there is not the dedicated workforce available (in the health system especially) with the required competencies or time to provide the outreach needed to facilitate communitybased nutrition services. Indeed, most of the donor-funded efforts to support community-based nutrition programmes use non-governmental organizations rather than formal health-system capacity to reach their project objectives.

There are no reliable data on how many CHW exist, regardless of what their nutrition orientation is or how well organized they are. The total of 1.3 million CHW worldwide reported by the WHO in $2010^{(48)}$ seems flawed, as $80 \%$ of these were in the Western Pacific Region and none were reported for the Americas for example, even though Brazil has 250000 as described below. In addition to which, Indonesia has a million volunteers organized through local government, Nepal has 50000 volunteers organized by the health service and Bangladesh has many thousands of volunteers organized by a plethora of non-governmental organizations. Scaling up CHW was considered a crucial stepping stone towards achievement of the Millennium Development Goals and the overarching aim of health for all in LMIC, and one million CHW would be needed for sub-Saharan Africa alone ${ }^{(49)}$; but this was something that just did not happen.

\section{Workforce organization}

Organizational difficulties are as large a hurdle to scaling up nutrition actions as the lack of PHN specialists, although the two are interrelated. Most of the country studies found that the structure of the existing nutrition workforce is multilevel and interdisciplinary. In Europe it has been found that the main constraining factors relate to the lack of a supportive policy environment, fragmented organizational structures and a workforce that is not cohesive enough to implement PHN strategic initiatives ${ }^{(50)}$. Depending on how the sectors are organized and the degree of decentralization of governance, a PHN specialist will be needed in the local government district planning office for example, to plan and then oversee the delivery of such interventions across sectors in the district. Then each sector will need a specialist in its central unit to oversee the way nutrition-sensitive and -specific interventions are delivered by its sectors across districts. Then a central unit, possibly in the Ministry of Planning, is needed to help plan, budget and oversee how all of this is developed and eventually to evaluate its implementation. This is the way that the management of the Nepal Multisectoral Nutrition Plan is organized for example ${ }^{(51)}$. However, no programme guidance exists (that we are aware of) that discusses these dimensions of multisectoral nutrition programme governance. In many of the countries studied central-level coordination has been strengthened, but coordination at the lower levels still seems to be particularly difficult. In many countries, such as Indonesia and Bangladesh for example, the existing workforce was largely underutilized. Furthermore none of the countries studied had in place a unified nutrition information system that could guide decision-making processes for the double burden of malnutrition across the different sectors and levels of government. In the absence of somebody responsible for nutrition at the district level, such an information system is not likely to be used to its maximum potential, and nutrition will continue to be everybody's business but nobody's responsibility.

Three broad barriers to multisectoral collaboration at international and national levels have been reiterated in the literature: (i) low political commitment, leadership and mobilization with poor accountability; (ii) sector-bound organizational structures and weak coordinating bodies, including a lack of targeted communication and/or advocacy campaigns; and (iii) lack of human resources and capacity to bridge the high-level policy aims and implementation-level realities ${ }^{(52-54)}$. These barriers resonate with the key themes identified from the nutrition policy and politics literature reviews ${ }^{(55)}$ which find that the basic causal level of malnutrition is dominated by the political economy of nutrition. Part of the evasiveness of understanding this level and breaking through the barriers of multisectoral work is that it has been understated in research compared with the underlying and immediate levels of causality. Three linked themes or elements: (i) knowledge and evidence; (ii) politics and governance; and (iii) capacity and resources, were also recognized as critical for building an enabling environment. An enabling environment is defined as 'political and policy processes' that build and sustain momentum for the effective implementation of actions that reduce malnutrition ${ }^{(56)}$. Without due consideration of these barriers and building and sharpening the skills of the PHN workforce to understand, facilitate and guide such multisectoral processes, a crucial element in its capacity for addressing malnutrition might well be missing. The competencies provided by the training of the PHN specialist, be it pre-service or in-service, have to go way beyond just knowing the biological and social dimensions of malnutrition and include 'showing how' and 'doing', demonstrating leadership and facilitating the work of others ${ }^{(57)}$.

A key challenge for scaling up community-based programmes lies in institutionalizing and mainstreaming community participation ${ }^{(58)}$. The most difficult aspect is ensuring the ongoing supportive supervision of the community mobilizers by health staff who carry out the outreach and facilitate their work ${ }^{(59,60)}$. To date, the largest and most successful programme in this regard is the Brazilian Family Health Program, which has integrated $250000 \mathrm{CHW}$ into its health services and institutionalized community health committees as part of municipal health services $^{(61)}$. This means that community participation does not become an alternative, but is an integral part of the 
state's responsibility for health-care delivery. These sorts of approaches are now being seen as the way forward for tackling obesity in the USA for example ${ }^{(62)}$.

\section{Workforce preparation}

There does not seem to be any authoritative source of information concerning graduate courses on nutrition, be it globally or regionally. The website of the International Union of Nutritional Sciences (IUNS)* has no information in this regard, nor does the WPHNA $†$ or the nutrition unit of the WHO $\$$ A US website that claims to be the number one directory of graduate schools§ lists some 370 nutrition graduate courses, of which 331 are campus based and thirty-four are online. Of these courses 361 offer graduate courses (Bachelor's and Master's level) and 101 offer doctorate courses. Of the campus graduate courses the great majority are in the USA and the UK, with some in Canada and Denmark and few in Asia. But the courses vary in nature from food science to dietetics and community nutrition, with just five having a title indicating that they provide specialized PHN training. A recent survey of professional training in nutrition in Central and Eastern Europe ${ }^{(63)}$ identified nutrition graduate courses in just seven countries, whereas seven countries had no such programmes, regardless of the type of nutrition being taught.

The most recent and comprehensive survey of nutrition teaching establishments carried out in LMIC was performed in the West Africa region ${ }^{(64)}$, where eighty-three nutrition degree programmes comprising thirty-two BSc programmes, thirty-four MSc programmes and seventeen $\mathrm{PhD}$ programmes were identified. While more than half of these programmes were in Nigeria, six countries (Cape Verde, Guinea-Bissau, Liberia, Mali, The Gambia and Togo) offered no nutrition degree programme. The programmes identified did not provide a comprehensive coverage of all essential aspects of human nutrition, being heavily oriented to food science (46\%), with little emphasis on PHN (24\%) or overnutrition (2\%). India has also been shown to have a huge gap in its nutrition teaching and training initiatives ${ }^{(65)}$, with PHN offered in no more than five of 190 institutes providing nutrition courses, and then only as specialization options or modules. Nutrition science in India has traditionally been under the domain of 'Home Sciences' and as such largely considered 'women's business'. The focus of most courses is on food science and technology, which may in part help explain why such a big PHN capacity gap exists in India.

On-the-job training to develop the workforce to act in nutrition at such a scale will obviously require new and/or unconventional methods. Training enough Master- and

*http://www.iuns.org/links-to-nutrition-resources (accessed July 2015). †http://wphna.org/ (accessed July 2015).

†http://www.who.int/nutrition/en/ (accessed July 2015).

§http://www.gradschools.com/search-programs/nutrition (accessed July 2015).
Bachelor-level graduates capable of creating the capacity needed with other workers (in health and other sectors) or for community mobilization in LMIC will require considerable investment over several decades, and in the meantime scaling up nutrition efforts cannot wait. While more nutritionists are trained and PHN gets better reflected in medical/nursing curricula, on-the-job training is necessary. In the meantime and in order to meet the challenge and provide sufficient human resources in the short term, people must be able to train 'on the job'. A mixture of distance learning and periodic coming together with tutors and mentors makes this both economically and logistically more feasible.

In-service training is the only option for providing guidance to the many health professionals at the periphery of health services who deliver nutrition-specific interventions, often without adequate technical preparation and/or equipment to do so. Systematic reviews of in-service nutrition training have found that it improves the nutrition counselling and child undernutrition management of health workers ${ }^{(66,67)}$. In-service nutrition training programmes existed in less than half of the countries in West Africa and continuing training efforts were mainly concentrated on staff at national and regional levels, leaving health staff at lower levels with inadequate capacities in nutrition. Furthermore, those countries taking steps to enhance the performance of health workers through in-service training and mentoring in nutrition were mainly doing so for the management of acute malnutrition. More often than not, in-service training only happens in LMIC if a donor provides the funding. Hence the importance of including funding for such training in all national nutrition plans. Indeed the development of a national nutrition workforce strategy and implementation plan should be an integral component of any National Nutrition Strategy, but none exist that we know of.

There is considerable material available for in-service training of health-sector workers in the nutrition actions needed to improve maternal and child undernutrition. These include a set of generic tools for programming and capacity development on community-based infant and young child feeding (IYCF) counselling developed by UNICEF. The basic instrument is a set of counselling cards ${ }^{(68)}$, aimed for use in diverse country contexts, and it comes with a package of tools to guide local adaptation, design, planning and implementation of community-based IYCF counselling and support services at scale. The WHO has developed a combined training course on growth assessment and IYCF counselling ${ }^{(69)}$ which includes a set of slides, a guidebook for the director of the course and a guide for the trainers, in addition to the participants' manual. The FAO has also developed e-learning courses for professionals working in food and nutrition security, social and economic development, and sustainable management of natural resources. $\|$ It provides learners

|| http://www.fao.org/elearning/\#/elc/en/home (accessed July 2015). 
with free access to content that can interest them and support them in their job. The courses cover a wealth of topics of global interest. They offer content for self-pace learning as well as materials for trainers and references to existing bibliography and online resources. The Core Group has also designed training material to assist in scaling up the Essential Nutrition Actions, which go beyond IYCF. This comprises a trilogy of materials including a Booklet on Key Essential Nutrition Actions Messages $^{(70)}$, the Essential Nutrition Actions Framework Training Guide for Health Workers ${ }^{(71)}$ and the Essential Nutrition Actions Framework Training Guide for Community Volunteers ${ }^{(72)}$. Menzies University in Australia, in a collaborative effort with other agencies, has also designed a course to strengthen the knowledge and skills of nutrition stakeholders to plan and implement contextually appropriate evidence-based nutrition interventions ${ }^{(73)}$. The course has four modules: (i) nutrition programming and planning; (ii) nutrition for infants and young children; (ii) nutrition for adolescent girls and women throughout the life cycle $^{(74)}$; and (iv) food security for families and communities. The University of Montreal, Department of Nutrition and the WHO Collaborating Centre on Nutrition Changes and Development have developed with partner universities of the Francophonie two Masterlevel online courses (in French) that can be accessed free of charge through its website.* Dietitians of Canada, the national body for dietitians in Canada, also has a 'learning on demand' webpage which features a series of modules under the 'population health' grouping, $\dagger$ many of which are of direct relevance to PHN.

Continuing professional development is another important area that must be considered when developing the PHN workforce to scale up nutrition. Competencies related to preventive nutrition interventions require practice in order to become more proficient. Perhaps the most important element of continuing professional development is ongoing supportive supervision. The supervision of the nutrition workforce essentially requires somebody well trained and competent in the various PHN-related tasks and capable of taking on such a 'supportive' role. These could and should be the local lead nutrition person at the health centre or district level, be they nutritionists or health professionals trained in nutrition. This is an area that all nutrition-related professional associations could/ should be promoting.

Cornell University offers online continuing education courses for nutrition and health-care professionals, including for some medical doctors, through the Cornell NutritionWorks. $\$$ After a decade it had over 15000 members from 178 countries. Online courses offered through Cornell NutritionWorks include as an example 'Preventing

*http://poleDFN.org (accessed July 2015).

†http://www.dietitians.ca/Learn/LearOnline-Co/Population-Health.aspx (accessed December 2015).

†http://www.nutritionworks.cornell.edu/home/ (accessed July 2015).
Childhood Obesity: An Ecological Approach', which is a 6-week facilitated course that provides fifteen continuing professional education units (CPEU) and has been offered three times per year since 2006. The completion rate for the 724 registered individuals was $86 \%$ for individual registrants and $97 \%$ for team registrants.

The UK Government Department for International Development's nutrition strategy ${ }^{(75)}$ has foreseen the need to strengthen capacity to design effective nutrition-related programmes within its humanitarian, health, livelihoods and social development professional cadres. To do this it is supporting the London School of Hygiene and Tropical Medicine to develop a distance learning course on multisectoral nutrition programming, $\S$ which is publicly available for three years from 2013. This Master-level module has been designed to explore the complicated problem of undernutrition, highlight its multisectoral causes and identify potential programmatic solutions through sixteen self-study sessions. No certification or tutorial support is provided however.

Several other innovative models have or are being developed, such as the approach used by the School of Public Health of the University of the Western Cape, South Africa. It has provided access to Master-level public health education through distance education for health professionals from approximately twenty African countries while they remain in post ${ }^{(76)}$. Improved availability of the Internet has revolutionized the possibilities for capacity building in $\mathrm{PHN}^{(77)}$; one such possibility is the proposal to develop a Public Nutrition Virtual University ${ }^{(78)}$, which is well advanced although still waiting funding. The aim of the Public Nutrition Virtual University is to establish a 'virtual faculty' that follows a common syllabus/approach, building on existing institutions in LMIC that would issue the certificates, providing these countries with a flexible resource of training, mentoring and support from external institutions while the local capacity is strengthened. Such an approach would also need to include support for a cascade process to develop capacity down to the village level.

Another new initiative is the global nutrition training platform, the eNutrition Academy. $\|$ The eNutrition Academy is backed by five founding partners: the African Nutrition Society, the American Society for Nutrition, the Federation of African Nutrition Societies, IUNS and the Nutrition Society of the UK and Ireland. Its aim is to help teach nutrition science to a new generation of nutritionists around the world free of charge; especially in parts of the world where people are most at risk of malnutrition such as Africa, South Asia and South America. This is one of the new initiatives developed by IUNS through its newly created Capacity Building Task Force ${ }^{(79)}$. The courses are still in development and so it is still early to see how this will develop, and whether they will be PHN oriented.

\$https://ble.lshtm.ac.uk/course/view.php?id=26 (accessed July 2015). || http://www.enutritionacademy.org (accessed July 2015). 
Mentoring, defined as 'a reciprocal, mutual and supportive learning relationship', is one more tool that could and should be used to strengthen workforce development in PHN. A study conducted among advanced-level public health nutritionists in Australia ${ }^{(80)}$ revealed that mentoring, from both peers and senior colleagues, was identified as a significant contributor to competency development. Evidence further indicates that mentoring creates opportunities for networking and access to resources, improves career and personal satisfaction, increases professional and interpersonal skills as well as confidence, and develops reflection for both the mentee and mentor ${ }^{(81)}$. A mentoring programme could be informal or formal and include one-to-one, group and peer mentoring models. Mentees often make contact with numerous experienced and supportive people, including role models, coaches, supervisors and mentors from different organizations, peer groups and academics from whom they seek guidance and advice ${ }^{(82)}$. It seems that even informal mentoring interactions can make a considerable contribution to professional development ${ }^{(83)}$. However, significant factors that have been identified as important for success in the mentoring relationship include formality, training of mentors and organizational support ${ }^{(84)}$. It seems certain that any future approach to workforce competency development in PHN would benefit by building in such mentoring initiatives.

\section{Conclusions and recommendations}

Whether the momentum being created for nutrition will translate into accelerated reduction of malnutrition (be it over or under) is still difficult to say, but this WPHNA Task Force notes that to date no major initiative or earmarked funding has been created to build the capacity needed to ensure that this happens. Perhaps the greatest challenge for the PHN specialist is providing guidance to the many health professionals at the periphery of health services to deliver nutrition-specific interventions and especially to enable them to build capacity at the community level. In most LMIC developing the peripheral health-service workforce and community capacity to act on nutrition quickly is going to be an enormous challenge.

Conclusions reached by the capacity building group meeting in Rio de Janeiro in 2012 are still valid and the WPHNA should continue to try to provide professional/ technical guidance to support country-level workforce development, including competence standards, curriculum guides, programme accreditation system, international certification system, job description templates and guidance on continuing professional development. The recommendations from the 2013 regional European Union/UNICEF workshop on nutrition capacity building in South and Southeast Asia, supported by WPHNA, are also further supported by the deliberation of this Task Force.
These are that in the short term (2-3 years) each of the LMIC wanting to scale up nutrition programmes should develop area-based programmes in a limited number of focused districts where PHN workforce capacity in all spheres of the analysis could be developed and applied. A hybrid distance learning model for PHN workforce managers' in-service training seems the best option. This would require: in-service training of available staff and supervisors initially by outside trainers; placement of a district-level nutrition professional under the district government to plan and coordinate multisectoral inputs; and the development of a district nutrition monitoring system. In addition post-training follow-up/mentoring needs to be organized, perhaps as part of the supervision of such PHN workers. Simultaneously, in the medium term (4-6 years), each country needs to develop its own academic PHN capacity for pre-service training through collaboration with regional institutions where it exists, as well as by sending a significant group of national staff to participate in 3-4-month graduate certificate programmes and a smaller group of promising junior professionals to enrol in 1-2-year Master-level courses in PHN.

Unless far greater attention is paid to the capacity development components of national nutrition plans, then efforts to scale up nutrition in LMIC are unlikely to achieve their declared objectives. The importance of funding for training programmes cannot be overemphasized. Advocacy is needed in order for the funds to be raised and nongovernmental organizations should make a substantive contribution as major employers of trained nutritionists ${ }^{(85)}$. The WPHNA Task Force believes that it could and should support such efforts, and some of the members (S.B. and S.J.A.) are currently involved in capacity development for scaling up nutrition work in Bangladesh funded by UNICEF. This has involved reviewing all of training curricula (pre- and post-service) of all categories of health providers; reviewing job descriptions of all categories to determine nutrition responsibilities; making field visits to get an overview of who is doing what from district to community level; and holding discussions with stakeholders at central level in order to investigate which competencies needed to be strengthened. Following that, all key competencies to be strengthened were listed and learning objectives as well as performance indicators and methods to assess them were defined. Existing training modules are still very much oriented on knowledge and not enough on skills. In addition, teaching methods are not always optimal during training; even though some training may be using/ promoting participatory methodology, the majority are in the lecture 'mode', which is difficult to change. Training modules are being developed and the training of trainers for starting the cascade training will take place later this year. The Task Force looks forward to being able to review the progress of these and other efforts being developed to build capacity for scaling up nutrition at its next meeting in Cape Town in 2016. 


\section{Acknowledgements}

Acknowledgements: A first draft of this paper was shared with members of the WPHNA Capacity Building Task Force at a meeting held in Oxford in September 2014. The discussions held at that meeting helped to shape the final version of this paper. Financial support: No financial support was received from any funding agency in the commercial or not-for-profit sectors. Bond University provided a small grant to the WPHNA to support the attendance of R.S. at the Oxford meeting. Conflict of interest: None. Authorship: R.S. carried out the initial search for bibliography and wrote the first draft of the paper assisted by R.H. and B.M., to which written comments and further bibliography were contributed by L.M.d.P., H.D., S.B., S.J.A. and D.S. All of the co-authors have verified and agreed to this final version elaborated by R.S. Ethics of buman subject participation: Not applicable.

\section{References}

1. Darnton-Hill I, Nishida C \& James WPT (2004) A life course approach to diet, nutrition, and the prevention of chronic disease. Public Health Nutr 7, 101-121.

2. Shrimpton R \& Rokx C (2013) The Double Burden of Malnutrition: A Review of Global Evidence. Health, Nutrition and Population (HNP) Discussion Paper. Washington, DC: World Bank.

3. World Health Organization, UNICEF \& World Bank (2012) UNICEF-WHO-World Bank Joint Child Malnutrition Estimates. Geneva: WHO.

4. Ng M, Fleming T, Robinson M et al. (2013) Global, regional, and national prevalence of overweight and obesity in children and adults during 1980-2013: a systematic analysis for the Global Burden of Disease Study 2013. Lancet 384, 766-781.

5. Stevens GA, Finucane MM, De-Regil LM et al. (2013) Global, regional, and national trends in haemoglobin concentration and prevalence of total and severe anaemia in children and pregnant and non-pregnant women for 1995-2011: a systematic analysis of population-representative data. Lancet Glob Health 1, e16-e25.

6. Lim SS, Vos T, Flaxman AD et al. (2012) A comparative risk assessment of burden of disease and injury attributable to 67 risk factors and risk factor clusters in 21 regions, 1990-2010: a systematic analysis for the Global Burden of Disease Study 2010. Lancet 380, 2224-2260.

7. Eckel RH, Alberti KG, Grundy SM et al. (2010) The metabolic syndrome. Lancet 375, 181-183.

8. Bloom DE, Cafiero ET, Jané-Llopis E et al. (2011) The Global Economic Burden of Noncommunicable Diseases. Geneva: World Economic Forum.

9. Swinburn BA, Sacks G, Hall KD et al. (2011) The global obesity epidemic: shaped by global drivers and local environments. Lancet 378, 804-814.

10. Popkin BM \& Slining MM (2013) New dynamics in global obesity facing low- and middle-income countries. Obes Rev 14, 11-20.

11. World Bank (2006) Repositioning Nutrition as Central to Development: A Strategy for Large Scale Action. Washington, DC: World Bank.

12. Scaling Up Nutrition Road Map Task Team (2010) A Road Map for Scaling-Up Nutrition (SUN). New York: UN.
13. Scaling Up Nutrition (2014) SUN Movement Annual Progress Report. http://scalingupnutrition.org/wp-content/ uploads/2014/11/SUN_Progress-Report_ENG_20141024_web_ pages03.pdf (accessed June 2015).

14. Mokoro Ltd (2015) Independent Comprehensive Evaluation of the Scaling Up Nutrition Movement: Final Report - Main Report and Annexes. Oxford: Mokoro Ltd.

15. Sixty-fifth World Health Assembly (2012) WHA Resolution 65.6. Agenda item 13.3. Maternal infant and young child nutrition. http://apps.who.int/gb/ebwha/pdf_files/WHA65/ A65_R6-en.pdf (accessed June 2015).

16. Sixty-fifth World Health Assembly (2012) A65/11. Annex 2. Comprehensive implementation plan on maternal, infant and young child nutrition. http://www.who.int/nutrition/ topics/WHA65.6_annex2_en.pdf (accessed June 2015).

17. World Health Organization (2013) Global Action Plan for the Prevention and Control of Noncommunicable Diseases 2013-2020. Geneva: WHO.

18. World Health Organization (2015) Maternal, Infant and Young Child Nutrition: Development of the Core Set of Indicators. Geneva: WHO.

19. Heaver R (2005) Strengthening Country Commitment to Human Development: Lessons from Nutrition. Washington, DC: World Bank.

20. Yngve A, Tseng M, Haapala I et al. (2012) A robust and knowledgeable workforce is essential for public health nutrition policy implementation. Public Health Nutr 15, 1979-1980.

21. Hughes R, Shrimpton R, Recine E et al. (2012) Empowering our profession (Commentary). World Nutr 3, issue 2, 3-54.

22. Shrimpton R, Hughes R, Recine E et al. (2014) Nutrition capacity development: a practice framework. Public Health Nutr 17, 682-688.

23. Hughes R \& Margetts B (2013) Indonesian Nutrition Capacity Assessment. Bangkok: UNICEF.

24. Shrimpton R \& Atwood SJ (2012) Nepal National and District Nutrition Capacity Assessment. Bangkok: UNICEF.

25. Knowles J \& Marks GC (2013) Nutrition Capacity Assessment in Bangladesh. Bangkok: UNICEF.

26. Shrimpton R, Atwood SJ, Sanders D et al. (2013) An Overview and Regional Perspective on the Assessment of Nutrition Capacity of National and Mid-Level Personnel Carried out in Three Asian Countries. Bangkok: UNICEF.

27. Bhutta ZA, Das JK, Rizvi A et al.; Lancet Nutrition Interventions Review Group; Maternal and Child Nutrition Study Group (2013) Evidence-based interventions for improvement of maternal and child nutrition: what can be done and at what cost? Lancet 382, 452-477.

28. Ruel MT \& Alderman H; Maternal and Child Nutrition Study Group (2013) Nutrition-sensitive interventions and programmes: how can they help to accelerate progress in improving maternal and child nutrition? Lancet 382, 536-551.

29. World Health Organization (2012) Population-Based Approaches to Childhood Obesity Prevention. Geneva: WHO.

30. Romon M, Lommez A, Tafflet M et al. (2009) Downward trends in the prevalence of childhood overweight in the setting of 12-year school- and community-based programmes. Public Health Nutr 12, 1735-1742.

31. Scaling Up Nutrition (2010) SUN Movement: Revised Road Map, September 2012. http://scalingupnutrition.org/ wp-content/uploads/2012/10/SUN-Movement-Road-MapSeptemeber-2012_en.pdf (accessed January 2010).

32. European Commission (2012) Communication from the Commission to the European Parliament and the Council. Enhancing Maternal and Child Nutrition in External Assistance: An EU Policy Framework. Brussels: European Commission.

33. Alderman H, Elder L, Goyal A et al. (2012) Improving Nutrition through Multi-Sectoral Approaches. Washington, DC: World Bank. 
34. Garret JL \& Natalicchio M (2011) Working Multisectorally in Nutrition: Principles, Practices and Case Studies. Washington, DC: International Food Policy Research Institute.

35. Levinson FJ \& Balarajan Y (2013) Addressing Malnutrition Multi-Sectorally: What Have We Learned from Recent International Experience? New York: UNICEF.

36. World Health Organization (2013) Global Nutrition Policy Review: What Does it Take to Scale up Nutrition Action? Geneva: WHO.

37. World Health Organization (2010) A Conceptual Framework for Action on the Social Determinants of Health. Social Determinants of Health Discussion Paper 2 (Policy and Practice). Geneva: WHO.

38. Mason JB, Sanders D \& Musgrove P (2006) Community health and nutrition programmes. In Disease Control Priorities in Developing Countries, 2nd ed., pp. 1053-1074 [DT Jamison, JG Bremen, AR Measham et al., editors]. Washington, DC: World Bank.

39. Mason J (2012) Essential Nutrition Actions. Improving Maternal-Newborn-Infant and Young Child Health and Nutrition. Geneva: WHO.

40. Bhutta ZA, Lassi ZS, Pariyo G et al. (2010) Global Experience of Community Health Workers for Delivery of Health Related Millennium Development Goals: A Systematic Review, Country Case Studies, and Recommendations for Integration into National Health Systems. Geneva: Global Health Workforce Alliance/WHO.

41. Leeman J, Calancie L, Hartman MA et al. (2015) What strategies are used to build practitioners' capacity to implement community-based interventions and are they effective?: a systematic review. Implement Sci 10, 80.

42. Pepping F (2010) The current capacity for training in public health nutrition in West Africa. Glob Public Health 5, Suppl. 1, S20-S41.

43. Sodjinou R, Bosu WK, Fanou N et al. (2014) A systematic assessment of the current capacity to act in nutrition in West Africa: cross-country similarities and differences. Glob Health Action 7, 24763.

44. Sodjinou R, Bosu WK, Fanou N et al. (2014) Nutrition training in medical and other health professional schools in West Africa: the need to improve current approaches and enhance training effectiveness. Glob Health Action 7, 24827.

45. DiMaria-Ghalili RA, Edwards M, Friedman G et al. (2013) Capacity building in nutrition science: revisiting the curricula for medical professionals. Ann N Y Acad Sci 1306, $21-40$.

46. Leslie FC \& Thomas S (2009) Competent to care: are all doctors competent in nutrition? Proc Nutr Soc 68, 296-299.

47. Fox A, Chenhall C, Traynor M et al. (2008) Public health nutrition practice in Canada: a situational assessment. Public Health Nutr 11, 773-781.

48. World Health Organization (2011) World Health Statistics 2011 - Table 6: Health Workforce, Infrastructure and Essential Medicines. Geneva: WHO.

49. Singh P \& Sachs JD (2013) 1 million community health workers in sub-Saharan Africa by 2015. Lancet 382, 363-365.

50. Kugelberg S, Jonsdottir S, Faxelid E et al. (2012) Public health nutrition workforce development in seven European countries: constraining and enabling factors. Public Health Nutr 15, 1989-1998.

51. Shrimpton R, Crum J, Basnet S et al. (2014) Documenting the Process of Developing the Nepal Multi-Sector Nutrition Plan and Identifying Its Strengths and Weaknesses. Report of a Research Project. Kathmandu: UNICEF/European Union.

52. Morris SS, Cogill B \& Uauy R; Maternal and Child Undernutrition Study Group (2008) Effective international action against undernutrition: why has it proven so difficult and what can be done to accelerate progress? Lancet $\mathbf{3 7 1}$, 608-621.

53. Bryce J, Coitinho D, Darnton-Hill I et al.; Maternal and Child Undernutrition Study Group (2008) Maternal and child undernutrition: effective action at national level. Lancet 371, 510-526.

54. Pelletier DL, Menon P, Ngo T et al. (2011) The nutrition policy process: the role of strategic capacity in advancing national nutrition agendas. Food Nutr Bull 32, 2 Suppl., S59-S69.

55. Nisbett N, Gillespie S, Haddad L et al. (2014) Why worry about the politics of childhood undernutrition? World Dev 64, 420-433.

56. Gillespie S, Haddad L, Mannar V et al.; Maternal and Child Nutrition Study Group (2013) The politics of reducing malnutrition: building commitment and accelerating progress. Lancet 382, 552-569.

57. Hughes R, Shrimpton R, Recine E et al. (2011) A competency framework for global public health nutrition workforce development: a background paper. http://www. wphna.org/htdocs/downloadsapr2012/12-03\%20WPHNA\% 20 Draft $\% 20$ competency\%20standards\%20report.pdf (accessed January 2016).

58. Lehmann U \& Sanders D (2007) Report on Community Health Workers: What Do We Know About Them? Evidence and Information for Policy. Geneva: WHO, Department of Human Resources for Health.

59. Hill Z, Dumbaugh M, Benton L et al. (2014) Supervising community health workers in low-income countries - a review of impact and implementation issues. Glob Health Action 7, 24085.

60. UNICEF (2012) Community IYCF Counselling Package: Supportive Supervision/Mentoring and Monitoring Community IYCF. New York: UNICEF.

61. Harris M \& Haines A (2010) Brazil's family health programme. BMJ 341, c4945.

62. Institute of Medicine (2012) Accelerating Progress in Obesity Prevention: Solving the Weight of the Nation. Washington, DC: National Academies Press.

63. Gurinović M, Novaković R, Šatalić Z et al. (2015) Professional training in nutrition in Central and Eastern Europe: current status and opportunities for capacity development. Public Health Nutr 18, 372-377.

64. Sodjinou R, Fanou N, Deart L et al.; Regional Nutrition Working Group (2014) Region-wide assessment of the capacity for human nutrition training in West Africa: current situation, challenges, and way forward. Glob Health Action 7, 23247.

65. Khandelwal S, Dayal R, Jha M et al. (2012) Mapping of nutrition teaching and training initiatives in India: the need for Public Health Nutrition. Public Health Nutr 15, 2020-2025.

66. Sunguya BF, Poudel KC, Mlunde LB et al. (2013) Nutriton training improves health workers nutrition knowledge and competence to manage child undernutrition: a systematic review. Front Public Health 1, 37.

67. Yousafzai AK, Rasheed MA, Daelmans B et al. (2014) Capacity building in the health sector to improve care for children nutrition and development. Ann N Y Acad Sci 1308, 172-182.

68. UNICEF (2012) The Community Infant and Young Child Feeding (IYCF) Counselling Package: Counselling Cards. New York: UNICEF; available at http://www.unicef.org/ nutrition/files/counseling_cards_Oct._2012small.pdf

69. World Health Organization (2012) Combined Course on Growth Assessment and IYCF Counselling. Geneva: WHO.

70. Guyon AB \& Quinn VJ (2011) Booklet on Key Essential Nutrition Actions Messages. Washington, DC: Core Group; available at https://www.thp.org/files/Booklet_of_Key_ ENA_Messages_complete_for_web.pdf

71. Guyon AB \& Quinn VJ (2011) Essential Nutrition Actions Framework Training Guide for Health Workers. 
Washington, DC: Core Group; available at http://www. coregroup.org/storage/Nutrition/ENA/IIA._HW_Training Guide_complete.pdf

72. Guyon AB \& Quinn VJ (2011) Essential Nutrition Actions Framework Training Guide for Community Volunteers. Washington, DC: Core Group; available at http://www. coregroup.org/storage/Nutrition/ENA/III._CV_Training_Guide_ complete.pdf

73. Grieve H (2013) Building the capacity of public health leaders and practitioners to use global evidence to develop nutrition programs and policy in Timor Leste. Compass, March 2013 issue. http://www.wchknowledgehub. com.au/sites/default/files/SC_Nutrition_March13.pdf (accessed January 2016).

74. Grieve H (2012) Nutrition and food security - approaches to improving the health of women and children. Nutrition for adolescent girls and women throughout the lifecycle. http:// www.wchknowledgehub.com.au/sites/default/files/Short CourseReport_AdolescentGirls\&WomenThroughoutLifecycle. pdf (accessed January 2016).

75. Department for International Development (2011) Scaling Up Nutrition: The UK's Position Paper on Undernutrition. London: DFID.

76. Alexander L, Igumbor EU \& Sanders D (2009) Building capacity without disrupting health services: public health education for Africa through distance learning. Hum Resour Health 7, 28.
77. Geissler C (2015) Capacity building in public health nutrition. Proc Nutr Soc 74, 430-436.

78. Mason J (2011) PNVU Public Nutrition Virtual University. http://www.tulane.edu/ internut/PNVU/PNVU\%20Home. html (accessed January 2016)

79. Lartey A (2013) Message from the President. http://www.iuns. org/home/message-from-the-president/ (accessed January 2016).

80. Palermo C \& McCall L (2008) The role of mentoring in public health nutrition workforce development. Perspectives of advanced-level practitioners. Public Health Nutr 11, 801-806.

81. Palermo C, Hughes R \& McCall L (2010) An evaluation of a public health nutrition workforce development intervention for the nutrition and dietetics workforce. J Hum Nutr Diet 23, 244-253.

82. Nolinske T (1995) Multiple mentoring relationships facilitate learning during fieldwork. Am J Occup Ther $\mathbf{4 9}$, 39-43.

83. Bally JM (2007) The role of nursing leadership in creating a mentoring culture in acute care environments. Nurs Econ 25, 143-148.

84. Walker WO, Kelly PC \& Hume RF (2002) Mentoring for the new millennium. Med Educ 7, 15.

85. Delisle H (2012) Empowering our profession in Africa (Commentary). World Nutr 3, issue 6, 269-284. 